\title{
Effect of graphite die geometry on energy consumption during spark plasma sintering of zirconium diboride
}

\author{
Farhad Sadegh Moghanlou ${ }^{a, *}$, Mohammad Vajdi ${ }^{\text {a }}$, Milad Sakkaki ${ }^{\text {a }}$, Shahla Azizi ${ }^{\text {b }}$ \\ ${ }^{a}$ Department of Mechanical Engineering, University of Mohaghegh Ardabili, Ardabil, Iran \\ ${ }^{b}$ Institute of Biomedical Engineering, University of New Brunswick, Fredericton, Canada
}

\begin{abstract}
A B S T R A C T
The present work aims to investigate the geometrical parameters of the graphite die on energy consumption needed for sintering of a $\mathrm{ZrB}_{2}$ sample. The Maxwell and electrical charge conservation equations are solved to obtain the electrical potential and current of the system. The governing equations are discretized by the Galerkin method and solved using the finite element method. The electric current distribution is obtained at each geometry and the temperature contours are obtained. The results showed that the height of die has a direct effect on power consumption. This can be attributed to the increased electric resistance and consequent increased Joule heating. On the other hand, increasing the die height resulted in more uniform temperature distribution through the sintered sample.
\end{abstract}

KEYWORDS

(C) 2021 The Authors. Published by Synsint Research Group.

\section{Introduction}

Owing to the concerns about the environmental issues and lack of fossil fuel resources, it is needed to enhance the performance of the working devices $[1,2]$. The energy saving may be obtained by introducing new operational methods [3] or increasing the efficiency of the devices using passive or active enhancement methods [4-6]. Manufacturing technology consumes a high percentage of energy, therefore investment in this area may result in remarkable energy saving. Among the wide range of manufacturing methods, sintering is a very useful method that has attracted more attention in the product of material that is hard to shape or have high melting points [7]. However, this method needs a high amount of energy. Among the different methods of sintering, spark plasma sintering (SPS) has attracted more attention, recently $[8,9]$. The SPS is a densification method in which rapid heating is generated using a high electric current $[10,11]$. The ceramic powder is pressed uniaxially inside the graphite die. The electric current generates by applying a pulsed low DC electric potential. The rapid heating as a result of the Joule effect improves densification of the ceramic at working temperatures, which are typically lower than the temperatures needed for pressureless methods [12-14]. Also, the lower process time minimizes grain growth. The fine-grained microstructures and also the metastable phases may disappear in other types of sintering, however, the SPS method is capable of retaining these structures [15].

The SPS method is investigated widely both experimentally and numerically. The experimental methods have some drawbacks such as costs, and related uncertainties. On the other hand, it is difficult or sometimes impossible to get data in any position of the sintering setup. Numerical methods are powerful techniques, that their ability has proved in almost all branches of science including heat and mass transfer [16,17], biomechanics [18], manufacturing processes [19-21], etc. Employing the numerical methods help to find a proper sintering condition and have better control on the microstructure of the sintered samples. [22-26].

Muñoz, and Anselmi-Tamburini [27] employed a numerical method to investigate the temperature distribution in spark plasma sintering (SPS). They also investigated the resulted stress of this process and showed that the electrical conductivity of the sample directly affects the current distribution of the whole system. At a steady-state condition, the temperature remained constant, however as the

\footnotetext{
* Corresponding author. E-mail address: F_moghanlou@uma.ac.ir (F. Sadegh Moghanlou) Received 1 March 2021; Received in revised form 24 April 2021; Accepted 25 April 2021.

Peer review under responsibility of Synsint Research Group. This is an open access article under the CC BY license (https://creativecommons.org/licenses/by/4.0/). https://doi.org/10.53063/synsint.2021.117
} 
electricity turned off, the progressive temperature drop is observed. This decrease comes back to the conduction and radiation-based losses. They also reported that the difference in thermal expansion of the sample and surrounding parts has a direct effect on resulted stresses. Yushin et al. [28] investigated the temperature distribution and mechanical stresses in the sample and the mold numerically in alumina and tungsten carbide powders. In the samples made of aluminum oxide, they found a considerable diagonal temperature gradient. They proposed several methods for homogenizing the temperature field such as the extended hold at a maximum temperature during the sintering process or the application of a matrix of different shapes and sizes or made of different materials. Manièrea et al. [29] used an electrothermal simulation of the SPS process with finite element modeling to investigate electro-thermal contacts in the spark plasma sintering process. They claimed that the electrical contact resistance (ECR) led to the temperature rise of the overall system (die, punches, and sample). Song et al. [30] used the finite element method (FEM) for the one-step-forming process of spark plasma sintering considering local densification of powder material. They found that increasing the sintering pressure decreased the sintering temperature and temperature gradient. They found the considerable effect of thermal expansion of the die and powder compact on stress distributions. They also reported that the temperature distribution affected the mechanical stresses and that the applied external pressure played an important role in the densification. Zavaliangos et al. [31] used both experimental and numerical simulations to obtain the temperature distribution in the specimen/die/punch setup during field-activated sintering. They found a considerable radial and axial temperature gradients in the specimen. Furthermore, they reported that the punches experienced the highest temperatures while the minimum value was on the outer die surface. Their results showed that there was almost linear relation between the

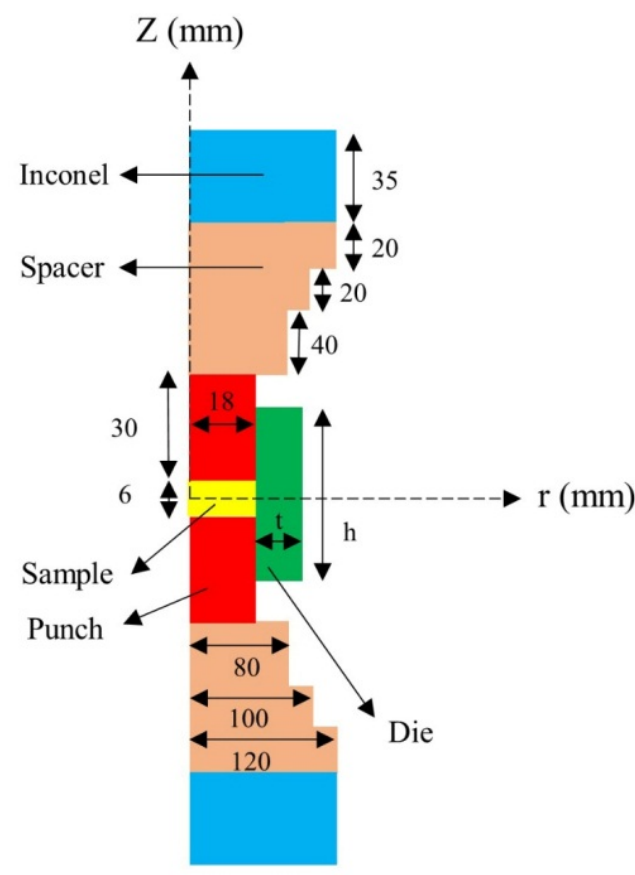

Fig. 1. Geometrical specifications and parameters of SPS system. die surface and the inside temperatures that can be useful for calibration of the temperature inside the specimen against the die surface temperature.

The literature review shows a wide range of researches in the application of SPS as a manufacturing method. However, the energy consumption of SPS is not investigated properly. An SPS setup consists of the different parts which play a direct role in energy consumption. Considering the importance of energy and related problems, the present work focuses on the effect of geometrical parameters on energy consumption, during the sintering of a $\mathrm{ZrB}_{2}$ sample. Zirconium diboride is one of the UHTCs family that has a high melting point, high strength, and great resistance against harsh working conditions. The wonderful properties of this material have led to use in the aerospace industry and foundry or electrical devices such as electrode or crucible materials for molten metal contacts [32-34]. The governing equations of the electric current and heat diffusion are solved numerically using the finite element method and temperature distribution is obtained. The energy consumption needed for sintering is obtained using applied voltage and consumed electric current.

\section{Methodology}

\subsection{Geometry}

The computational domain is selected the same as the reference [35]. This system includes a graphite die in which the ceramic powders are poured in it and is pressed uniaxially to produce a dense product. The other parts of the systems are graphite punches, spacers, and upper and lower electrodes. The upper and lower parts of the system are made by Inconel and cooled by water flow. The detailed information can be found in Fig. 1. The present work aims to investigate the effect of die geometry on energy consumption during SPS of a $\mathrm{ZrB}_{2}$ sample. The height of the graphite die is shown by "h" and the thickness by " $\mathrm{t}$ ".

\subsection{Governing equations}

Due to the applied electric potential, an electric current passes through the system. The intrinsic resistance against the electron passages results in heat generation. To simulate this phenomenon, the Maxwell and electric charge conservation equations should be solved to obtain the electric potential distribution and the electric current at each point. At the same time, the heat diffusion equation is needed to provide the temperature distribution. Since the properties are temperature dependent, therefore these equations should be coupled and solved simultaneously.

Maxwell's equation is as [36]:

$$
\nabla \mathrm{J}=\nabla(\sigma \mathrm{E})=\nabla(-\sigma \nabla \mathrm{U})=0
$$

Where $\mathrm{J}$, is the current density, $\mathrm{E}$ is the electric field, $\mathrm{U}$ is the electrical potential, and $\sigma$ is the electrical conductivity of the used materials. The electric current equation is as:

$\frac{1}{\mathrm{r}} \frac{\partial\left(\mathrm{ri}_{\mathrm{r}}\right)}{\partial \mathrm{r}}+\frac{\partial \mathrm{i}_{\mathrm{z}}}{\partial \mathrm{z}}=0$

The current densities in $r$ and $z$ directions are given by $i_{r}$ and $i_{z}$, respectively.

The SPS devices generally generate the pulsed type electric potentials; therefore, the RMS (Root-mean-square) values of the voltage and the 
Table 1. The properties of the different parts of the SPS system as the function of temperature (T in Kelvin).

\begin{tabular}{|c|c|c|c|c|}
\hline Material & Graphite [29] & $\mathbf{A l}_{2} \mathbf{O}_{3}$ & $\mathbf{Z r B}_{2}[38,39]$ & Inconel [37] \\
\hline Heat capacity (J/Kg.K) & $\begin{array}{l}34.27+2.72 \times \mathrm{T} \\
-9.6 \times 10^{-4} \times \mathrm{T}^{2}\end{array}$ & $8.5 \times 10^{2}$ & $\begin{array}{l}2.52 \times 10^{-5} \times \mathrm{T} \\
-80.2 \times \mathrm{T}^{-1}+0.704\end{array}$ & $344+0.25 \times \mathrm{T}$ \\
\hline Density $\left(\mathrm{Kg} / \mathrm{m}^{3}\right)$ & $\begin{array}{l}1.9 \times 10^{3}- \\
1.414 \times 10^{-2} \mathrm{~T}\end{array}$ & $3.9 \times 10^{3}$ & $6.08 \times 10^{3}$ & $8.43 \times 10^{3}$ \\
\hline Thermal conductivity (W/m K) & $\begin{array}{l}82.85-0.06 \times \mathrm{T} \\
+2.58 \times 10^{-5} \times \mathrm{T}^{2}\end{array}$ & $\frac{39500}{T^{1.26}}$ & $60.316+0.0041 \times \mathrm{T}$ & $0.0157 \times \mathrm{T}+10.09$ \\
\hline Electric resistivity $(\Omega . \mathrm{m})$ & $\begin{array}{l}2.14 \times 10^{-5} \\
-1.34 \times 10^{-8} \times \mathrm{T} \\
+4.42 \times 10^{-12} \times \mathrm{T}^{2}\end{array}$ & $\frac{8.7 \times 10^{9}}{T^{4.82}}$ & $\begin{array}{l}0.0589 \mathrm{~T}+ \\
5.4894 \times 10^{-8}\end{array}$ & $\begin{array}{l}9.82 \times 10^{-7}+ \\
1.6 \times 10^{-10} \times \mathrm{T}\end{array}$ \\
\hline
\end{tabular}

current are used in the governing equations. The RMS value of the voltage is defined as [37]:

$\mathrm{U}_{\mathrm{RMS}}=\sqrt{\frac{1}{\mathrm{P}} \int_{\mathrm{t}-\mathrm{T}}^{\mathrm{t}} \mathrm{u}^{2}(\tau) \mathrm{d} \tau}$

where $\mathrm{u}$ shows the time-dependent voltage, $\mathrm{P}$ is the period of voltage function, and $\tau$ is the time. A similar function is used to find the RMS value of the current. The product of the electric current by the electric potential gives the joule heating which is used as a heat source in the heat diffusion equation.

The generated heat as a result of the Joule effect is defined as:

$\mathrm{q}_{\mathrm{i}}=\mathrm{J} . \mathrm{E}$

where $\mathrm{E}$ is the electric field.

The heat diffusion equation in cylindrical form is as:

$\rho \mathrm{C}_{\mathrm{p}} \frac{\partial \mathrm{T}}{\partial \mathrm{t}}=\frac{1}{\mathrm{r}} \frac{\partial}{\partial \mathrm{r}}\left(\mathrm{rk}_{\mathrm{r}} \frac{\partial \mathrm{T}}{\partial \mathrm{r}}\right)+\frac{1}{\mathrm{z}} \frac{\partial}{\partial \mathrm{z}}\left(\mathrm{rk}_{\mathrm{z}} \frac{\partial \mathrm{T}}{\partial \mathrm{z}}\right)+\mathrm{q}_{\mathrm{i}}$
Here, the thermal conductivities in $\mathrm{r}$ and $\mathrm{Z}$ directions are given by $\mathrm{k}_{\mathrm{r}}$ and $k_{z}$, respectively. The density is shown by $\rho$ and, whereas $C_{p}$ is chosen to denote the heat capacity. The temperature is given by $\mathrm{T}$.

\subsection{Material properties}

The temperature interval of the SPS is large; therefore, the temperaturedependent properties should be used in governing equations. The properties of the used materials in SPS as a function of temperature are given in Table 1.

\subsection{Boundary and initial conditions}

The governing equations are a series of differential equations that need related boundary and initial conditions to be completely solved. The applied boundary conditions of the present work are shown in Fig. 2. The outer surfaces of the device are considered as electrically insulated (brick red and yellow lines in Fig. 2). At the upper surface, the electric potential is used and the lower surface is connected to the ground (i.e.
Radiation to chamber wall $\varepsilon=0.8$ and electric insulation

Thin layer: thickness $0.1 \mathrm{~mm}$ thermal conductivity $0.04 \frac{W}{m \cdot K}$

Radiation to chamber wall $\varepsilon=0.67$ and electrical insulation

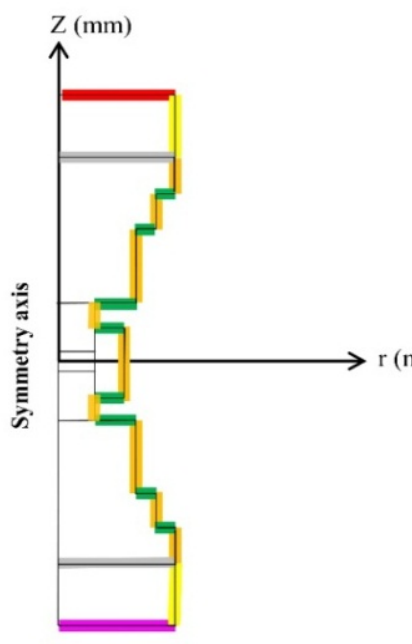
Convection heat transfer $\mathrm{h}=880 \frac{W}{m^{2} \cdot K}$
and ground $(v=\emptyset)$ $(\mathrm{mm})$

Thermal and electric insulation

Convection heat transfer $\mathrm{h}=880 \frac{\mathrm{W}}{\mathrm{m}^{2} \cdot K}$ and RMS voltage $\left(V_{R M S}\right)$

Fig. 2. Boundary conditions. 


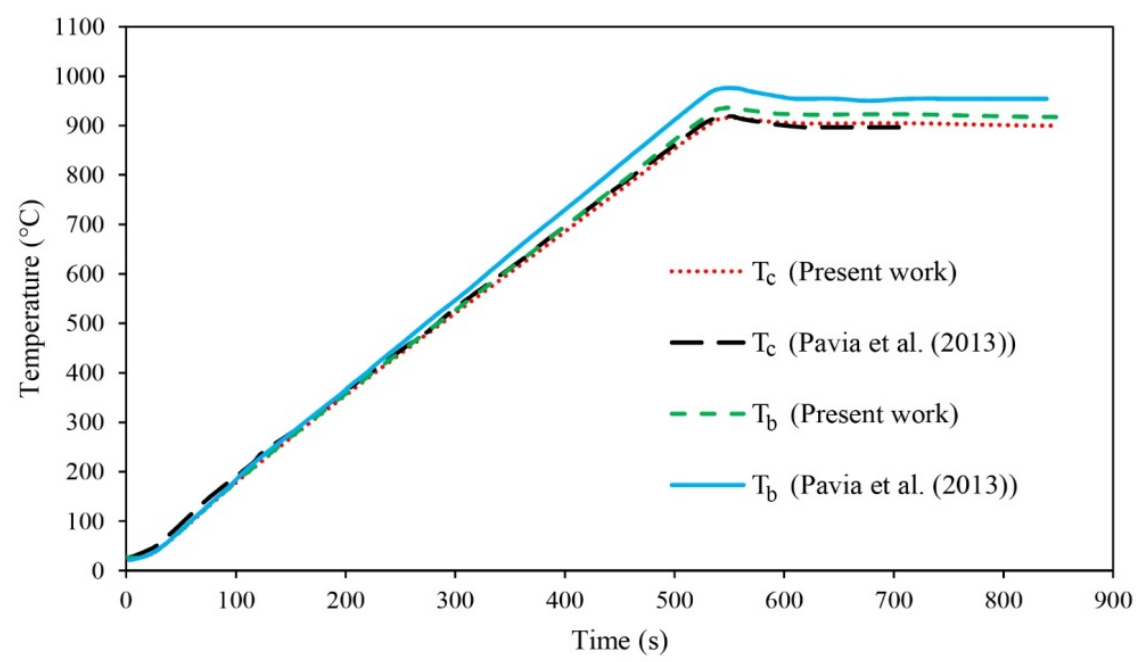

Fig. 3. Validation of the present work using the data provided by Pavia et al. [37].

$\mathrm{V}=0$ ). The upper and lower surfaces are cooled by water flow; therefore, the convective heat transfer boundary condition is the main mechanism of cooling (see Fig. 2) which is given by Newton cooling law as:

$$
\mathrm{q}_{\mathrm{c}}=\mathrm{h}_{\mathrm{c}}\left(\mathrm{T}_{\mathrm{s}}-\mathrm{T}_{\mathrm{w}}\right)
$$

Here, the dissipated heat flux by the water is shown by $q_{c}$ whereas the convection coefficient is shown by $h_{c}$. The surface and the water temperatures are shown by $T_{s}$ and $T_{w}$, respectively. Based on reference [35] the convection coefficient for both upper and lower surfaces is considered to be $h_{c}=880\left(W / m^{2} . K\right)$.

The sintering setup is embedded in a vacuum condition, therefore the heat losses from the side walls can be considered as only radiation. The heat transfer by radiation mechanism can be expressed as:

$$
\mathrm{q}_{\mathrm{r}}=\sigma_{\mathrm{s}} \cdot \varepsilon \cdot\left(\mathrm{T}_{\mathrm{e}}^{4}-\mathrm{T}_{\mathrm{a}}^{4}\right)
$$

Where the radiation heat flux is shown by $\mathrm{q}_{\mathrm{r}}$, the emissivity of material by $\varepsilon$ ( 0.8 for the graphite [24] and 0.67 for the Inconel [29]), and the Stefan-Boltzmann constant by $\sigma_{\mathrm{s}}$. The temperature of the emission surface is given by $T_{e}$ while $T_{a}$ shows the temperature of the chamber walls.

A thin layer with the thickness of $0.1 \mathrm{~mm}$ and thermal conductivity of $0.04(\mathrm{~W} / \mathrm{m} . \mathrm{K})$ is considered as the thermal contact at the interface of Inconel and spacer (blue lines in Fig. 2), a thin layer with an equivalent thickness of $0.1 \mathrm{~mm}$ and is considered [29]. According to Manière et al. [10], the electric contact resistance (ECR) becomes negligible at temperatures above $800{ }^{\circ} \mathrm{C}$ and pressures higher than $50 \mathrm{MPa}$. The

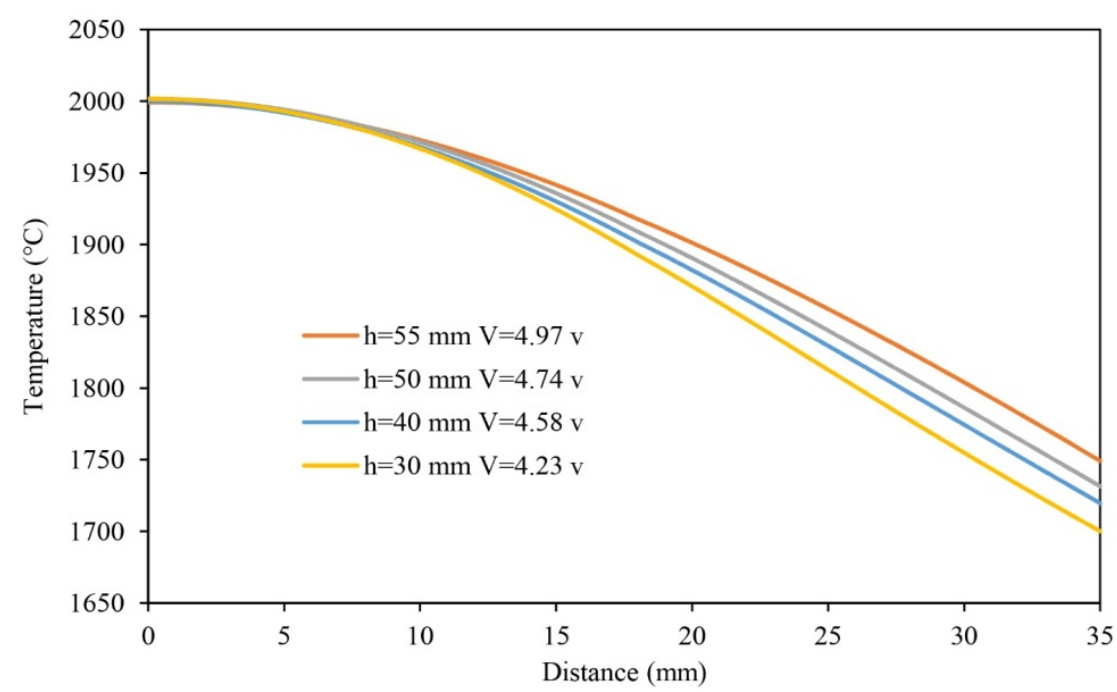

Fig. 4. Effect of die height on radial temperature distribution of the sintered sample. 


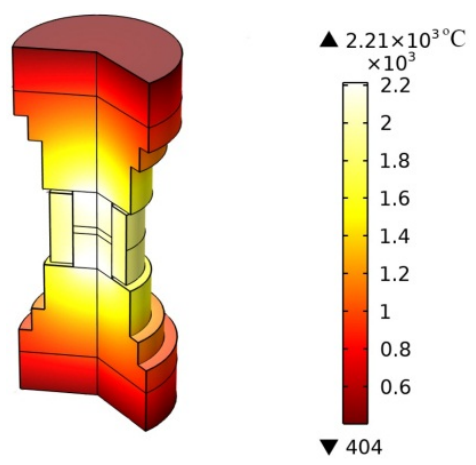

Fig. 5. The temperature contour in the three-dimensional view.

working pressure, in the present work, is in the order of $100 \mathrm{MPa}$, therefore the ECR is considered to be zero. Also, the sintering temperature is $2000{ }^{\circ} \mathrm{C}[37,39]$.

\section{Results and discussion}

The present work aims to investigate the effect of geometrical parameters on energy consumption during the SPS. In this regard, the thickness and the height of the graphite die are changed and the needed energy to reach the sintering temperature is calculated.

To validate the present simulation, a computational domain same as Pavia et al. [37] was considered and the temperature distribution was compared. The compared results are depicted in Fig. 3 which shows a good agreement. Therefore, the simulation can be developed to other geometries to obtain the temperature and current distribution and consequently the energy consumption by each case.

The effect of die height on radial temperature distribution in the sample is given in Fig. 4. In all cases, the center of the samples has the maximum temperature value and this quantity decreases toward the sample edge. Since both the $\mathrm{ZrB}_{2}$ and graphite are electrically conductive, the Joule effect results in heat generation in all parts. As the height of the die increases, the outer surface gets higher temperatures. In other words, as the height increases, a more uniform temperature can be obtained. The passing electric current in the die also generates heat. The electric resistance has a direct relation with the length of the path where the electrons pass. The outer surface of the system is subjected to vacuum and the heat dissipates to the surrounding via radiation. It seems that higher values of heat generation in the die with bigger height compensate some part of the heat losses as a result of radiation. The temperature contour in a three-dimensional view is shown in Fig. 5. The cooling by water brings the temperature to its lowest value, whereas the center of the system has the maximum value. The temperature contours and the related electric current streamlines are depicted in Fig. 6. It is clear that the current lines in shorter dies are more intense which result in a higher temperature zone near the $\mathrm{ZrB}_{2}$ sample, whereas, in the higher die, the electrons find a larger cross section to pass therefore the current lines are far apart which result in more uniform current distribution and consequently more uniform temperature distribution.

The effect of die thickness on radial temperature distribution is depicted in Fig. 7. The results assert a little difference between the obtained temperatures. The current streamlines and related temperature countors for two thicknesses are depicted in Fig. 8. The thickness of the a)

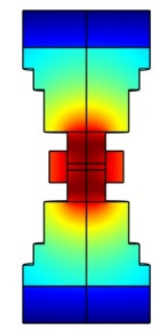

c)

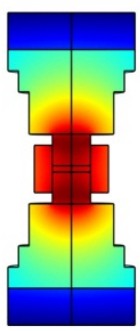

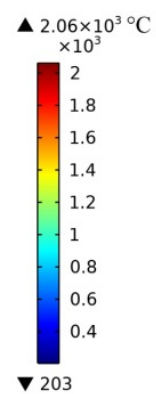

b)
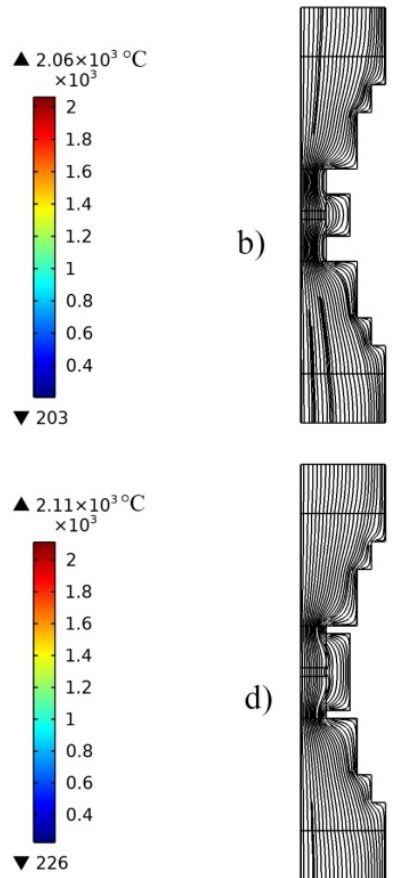

Fig. 6. Temperature countors and electric current lines for two different height of the die. 


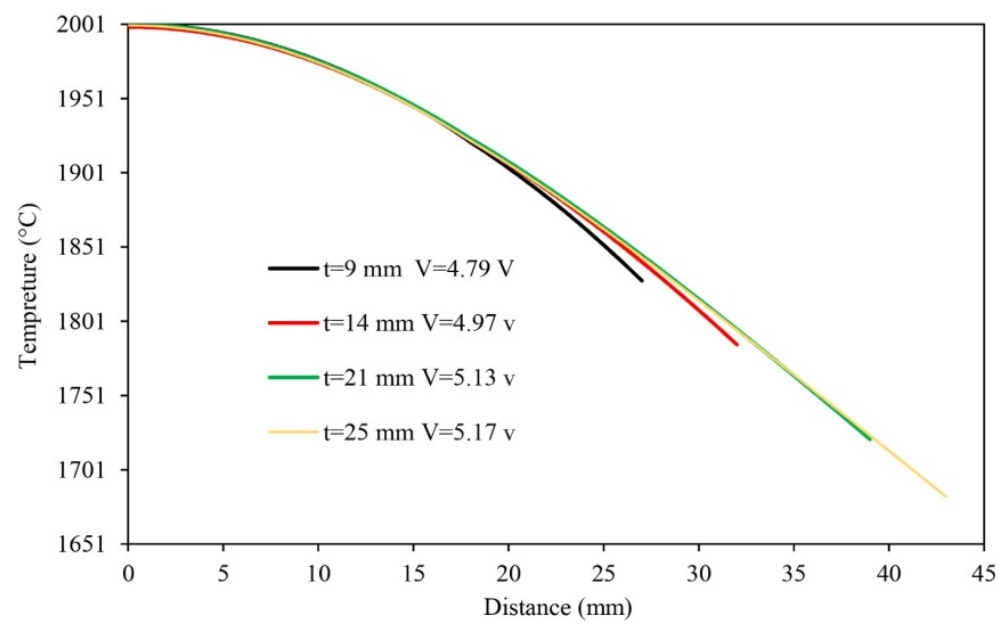

Fig. 7. Radial temperature distribution versus die thickness.

die plays a direct role in current density. Referring to Fig. 8, the current lines in the thicker die are more uniform whereas, in the thinner die, the current intensity is higher in the sample. Increasing the die thickness provides a higher cross section for electrons flow. The uniformity in current density results in more uniform temperature distribution. In other words, the nonuniform temperature distribution may result in higher thermal stresses and consequently concerns about the failure of the SPS system.

The energy consumption via the height of the die is depicted in Fig. 9.
It is clear that by increasing the die height, the power consumption increases. As mentioned before, increasing the die height results in an increase in the overall resistance of the system and consequently increased power consumption

The power consumption versus die thickness is depicted in Fig. 10. It can be seen that for the thicker die, a higher rate of energy is needed. Referring to Fig. 8, as the thickness increases, the total cross section for passing the electric current increases. The cross section is in inverse relation to electric resistance. Therefore, for a constant electric a)
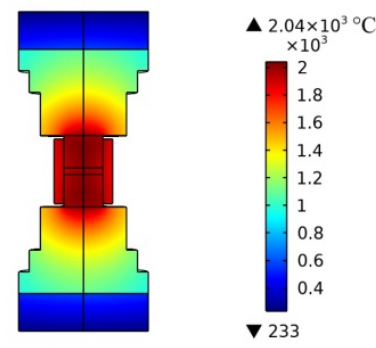

c)

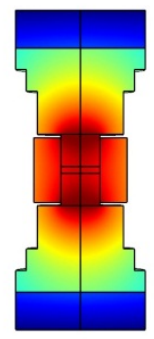

b)

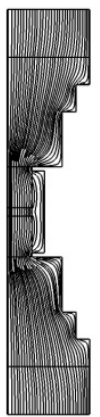

d)

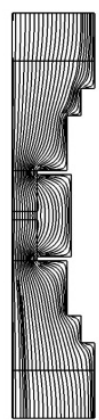

Fig. 8. Temperature contours and current lines versus die thickness. 


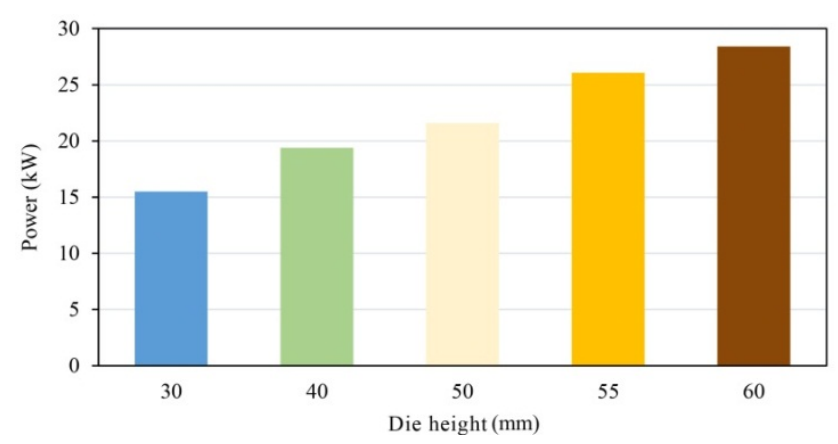

Fig. 9. Energy consumption versus die height.

potential difference, as the cross section increases the net current increases and results in higher power consumption.

As a comprehensive conclusion, the electric current and the subsequent power consumption for suggested geometries are gathered in Table 2 . Also as a special case, the outer surface of the system is isolated to prevent heat loss as a result of radiation. This case is applied for the case of $\mathrm{h}=60 \mathrm{~mm}$ and $\mathrm{t}=17 \mathrm{~mm}$.

In the base case, the electric current and electric potential are $5625.4 \mathrm{~A}$, and $5.05 \mathrm{~V}$, respectively. In the case of height variation, where the thickness is kept at $17 \mathrm{~mm}$, by increasing the height of the die, the needed current for sintering increases. The increased current result in higher power consumption. As a conclusion, increasing the die height increases energy consumption.

For a constant height of $60 \mathrm{~mm}$, as the thickness increases the energy needed for sintering gets higher values. The highest value for energy is obtained at the case of $\mathrm{h}=60 \mathrm{~mm}$ and $\mathrm{t}=25 \mathrm{~mm}$.

Referring to Table 2, remarkable energy consumption is obtained in the case of insulation. Here, the outer surface of the system is insulated against radiation. The energy consumption is $9.8026 \mathrm{~kW}$ which is $35 \%$ of the standard case without insulation. It means that the insulation of the system against radiation may result in $65 \%$ energy saving and related costs. Also, the needed current and electric potentials for this case are $3391.9 \mathrm{~A}$ and $2.89 \mathrm{~V}$, respectively.

Table 2. Electric current and energy consumption at different heights and thicknesses.

\begin{tabular}{cccc}
\hline Type & $\mathbf{I}(\mathbf{A})$ & $\mathbf{V}(\mathbf{v})$ & $\mathbf{P}(\mathbf{k W})$ \\
\hline Base & 5625.4 & 5.05 & 28.40827 \\
\hline insulation & 3391.9 & 2.89 & 9.802591 \\
\hline $\mathrm{h}=30 \mathrm{~mm}$ & 3667.3 & 4.23 & 15.51268 \\
\hline $\mathrm{h}=40 \mathrm{~mm}$ & 4235.3 & 4.58 & 19.39767 \\
\hline $\mathrm{h}=50 \mathrm{~mm}$ & 4555.2 & 4.74 & 21.59165 \\
\hline $\mathrm{h}=55 \mathrm{~mm}$ & 5245.9 & 4.97 & 26.07212 \\
\hline $\mathrm{t}=9 \mathrm{~mm}$ & 5062.3 & 4.79 & 24.24842 \\
\hline $\mathrm{t}=14 \mathrm{~mm}$ & 5469.1 & 4.97 & 27.18143 \\
\hline $\mathrm{t}=21 \mathrm{~mm}$ & 5767.8 & 5.13 & 29.58881 \\
\hline $\mathrm{t}=25 \mathrm{~mm}$ & 5848.2 & 5.17 & 30.23519 \\
\hline
\end{tabular}

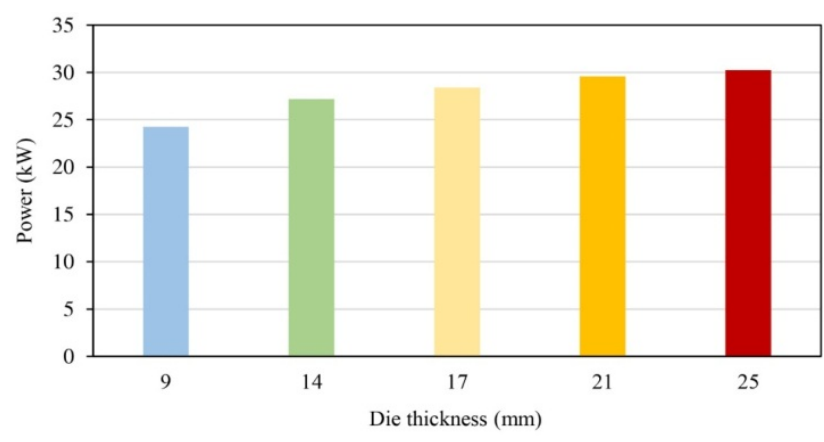

Fig. 10. Energy consumption versus die thickness.

\section{Conclusions}

A numerical simulation is performed to investigate the effect of graphite dies geometry on energy consumption during the sintering of $\mathrm{ZrB}_{2}$. Space charge energy conversion and heat diffusion equation are solved numerically using the finite element method. The results showed that the higher height of the die results in a more uniform temperature distribution in the sintered sample. However, it needs more energy consumption. Using a thicker graphite die needs more sintering energy. This can be attributed to the increased cross section for electric current and subsequently increased power consumption. The thickness of the die showed a negligible effect on temperature uniformity. Radiation is the main mechanism of the heat losses, therefore, as a test case, the outer surface of the system was isolated against the radiation. A $65 \%$ energy saving was obtained for sintering of the $\mathrm{ZrB}_{2}$. This remarkable reduction in energy consumption, not only decreases the electricity cost but also may result in an increased life span of the SPS system.

\section{References}

[1] F. Yekani, S. Abdi Aghdam, E. Sadegh Moghanlo, Experimental study of the performance and exhaust gas emissions response of A spark ignition engine to adding natural gas to gasoline in $\mathrm{CR}=11$., Int. J. Ind. Math. 11 (2019) 307-317.

[2] M. Namazizadeh, M. Talebian Gevari, M. Mojaddam, M. Vajdi, Optimization of the Splitter Blade Configuration and Geometry of a Centrifugal Pump Impeller using Design of Experiment, J. Appl. Fluid Mech. 13 (2020) 89-101.

[3] T. Gholizadeh, M. Vajdi, H. Rostamzadeh, Freshwater and cooling production via integration of an ethane ejector expander transcritical refrigeration cycle and a humidification-dehumidification unit, Desalination. 477 (2020) 114259.

[4] S. Noorzadeh, F. Sadegh Moghanlou, M. Vajdi, M. Ataei, Thermal conductivity, viscosity and heat transfer process in nanofluids: A critical review, J. Compos. Compd. (2020).

[5] M. Ataei, F. Sadegh Moghanlou, S. Noorzadeh, M. Vajdi, M. Shahedi Asl, Heat transfer and flow characteristics of hybrid A12O3/TiO2-water nanofluid in a minichannel heat sink, Heat Mass Transf. 56 (2020) 2757-2767.

[6] F. Sadegh Moghanlou, S. Noorzadeh, M. Ataei, M. Vajdi, M. Shahedi Asl, E. Esmaeilzadeh, Experimental investigation of heat transfer and pressure drop in a minichannel heat sink using $\mathrm{A} 12 \mathrm{O} 3$ and TiO2-water nanofluids, J. Brazilian Soc. Mech. Sci. Eng. 42 (2020) 315. 
[7] B. Basu, G.B. Raju, A.K. Suri, Processing and properties of monolithic $\mathrm{TiB}_{2}$ based materials, Int. Mater. Rev. 51 (2006) 352-374.

[8] B.M. Moshtaghioun, D. Gómez-García, A. Domínguez-Rodríguez, Spark plasma sintering of titanium nitride in nitrogen: Does it affect the sinterability and the mechanical properties, J. Eur. Ceram. Soc. 38 (2018) 1190-1196.

[9] F. Sadegh Moghanlou, M. Vajdi, H. Jafarzadeh, Z. Ahmadi, A. Motallebzadeh, F. Sharifianjazi, M. Shahedi Asl, M. Mohammadi, Spark plasma sinterability and thermal diffusivity of TiN ceramics with graphene additive, Ceram. Int. 47 (2021) 10057-10062.

[10] C. Maniere, A. Pavia, L. Durand, G. Chevallier, V. Bley, K. Afanga, A. Peigney, C. Estournès, Pulse analysis and electric contact measurements in spark plasma sintering, Electr. Power Syst. Res. 127 (2015) 307-313.

[11]E.A. Olevsky, W.L. Bradbury, C.D. Haines, D.G. Martin, D. Kapoor, Fundamental Aspects of Spark Plasma Sintering: I. Experimental Analysis of Scalability, J. Am. Ceram. Soc. 95 (2012) 2406-2413.

[12] U. Anselmi-Tamburini, S. Gennari, J.E. Garay, Z.A. Munir, Fundamental investigations on the spark plasma sintering/synthesis process, Mater. Sci. Eng. A. 394 (2005) 139-148.

[13] B. Nili, G. Subhash, Influence of porosity and pellet dimensions on temperature and stress inhomogeneities during spark plasma sintering of ceramic fuel, Ceram. Int. 45 (2019) 7376-7384.

[14] G. Maizza, S. Grasso, Y. Sakka, T. Noda, O. Ohashi, Relation between microstructure, properties and spark plasma sintering (SPS) parameters of pure ultrafine WC powder, Sci. Technol. Adv. Mater. 8 (2007) 644-654.

[15] I.G. Crouch, G.V. Franks, C. Tallon, S. Thomas, M. Naebe, Glasses and ceramics, in: Sci. Armour Mater. Elsevier, (2017)331-393.

[16] T. Dehghani, F. Sadegh Moghanlou, M. Vajdi, M. Shahedi Asl, M. Shokouhimehr, M. Mohammadi, Mixing enhancement through a micromixer using topology optimization, Chem. Eng. Res. Des. 161 (2020) 187-196.

[17] Z.N. Meng, P. Zhang, Experimental and numerical investigation of a tube-in-tank latent thermal energy storage unit using composite PCM, Appl. Energy. 190 (2017) 524-539.

[18] Z. Hajati, F. Sadegh Moghanlou, M. Vajdi, E. Razavi, S. Matin, Fluid Structure Interaction of blood flow around a vein valve, BioImpacts. 10 (2020) 169-175.

[19] M. Fattahi, M. Najafi Ershadi, M. Vajdi, F. Sadegh Moghanlou, A. Sabahi Namini, M. Shahedi Asl, On the simulation of spark plasma sintered TiB2 ultra high temperature ceramics: A numerical approach, Ceram. Int. 46 (2020) 14787-14795.

[20] M. Sakkaki, F. Sadegh Moghanlou, M. Vajdi, M. Shahedi Asl, M. Mohammadi, M. Shokouhimehr, Numerical simulation of heat transfer during spark plasma sintering of zirconium diboride, Ceram. Int. 46 (2020) 4998-5007.

[21] K. Vaferi, M. Vajdi, S. Nekahi, S. Nekahi, F. Sadegh Moghanlou, M. Shahedi Asl, M. Mohammadi, Thermo-mechanical simulation of ultrahigh temperature ceramic composites as alternative materials for gas turbine stator blades, Ceram. Int. 47 (2020) 567-580.

[22] R. Orrù, R. Licheri, A.M. Locci, A. Cincotti, G. Cao, Consolidation/synthesis of materials by electric current activated/assisted sintering, Mater. Sci. Eng. R Reports. 63 (2009) $127-287$.

[23] J.G. Santanach, A. Weibel, C. Estournès, Q. Yang, C. Laurent, A. Peigney, Spark plasma sintering of alumina: Study of parameters, formal sintering analysis and hypotheses on the mechanism(s) involved in densification and grain growth, Acta Mater. 59 (2011) 1400-1408.

[24] K. Vanmeensel, A. Laptev, J. Hennicke, J. Vleugels, O. Vanderbiest, Modelling of the temperature distribution during field assisted sintering, Acta Mater. 53 (2005) 4379-4388.

[25] M. Shahedi Asl, Z. Ahmadi, A. Sabahi Namini, A. Babapoor, A. Motallebzadeh, Spark plasma sintering of $\mathrm{TiC}-\mathrm{SiCw}$ ceramics, Ceram. Int. 45 (2019) 19808-19821.

[26] K. Sairam, J.K. Sonber, T.S.R.C. Murthy, C. Subramanian, R.K Fotedar, P. Nanekar, R.C. Hubli, Influence of spark plasma sintering parameters on densification and mechanical properties of boron carbide, Int. J. Refract. Met. Hard Mater. 42 (2014) 185-192.

[27] S. Muñoz, U. Anselmi-Tamburini, Temperature and stress fields evolution during spark plasma sintering processes, J. Mater. Sci. 45 (2010) 6528-6539.

[28] D.I. Yushin, A. V. Smirnov, P.Y. Peretyagin, R. Torrecillas, Cutting tools: finite element modeling of spark plasma sintering to improve their quality, Mech. Ind. 16 (2015) 713.

[29] C. Manière, A. Pavia, L. Durand, G. Chevallier, K. Afanga, C. Estournès, Finite-element modeling of the electro-thermal contacts in the spark plasma sintering process, J. Eur. Ceram. Soc. 36 (2016) 741-748.

[30] Y. Song, Y. Li, Z. Zhou, Y. Lai, Y. Ye, A multi-field coupled FEM model for one-step-forming process of spark plasma sintering considering local densification of powder material, J. Mater. Sci. 46 (2011) 5645-5656.

[31] A. Zavaliangos, J. Zhang, M. Krammer, J.R. Groza, Temperature evolution during field activated sintering, Mater. Sci. Eng. A. 379 (2004) 218-228.

[32] M. Mallik, A.J. Kailath, K.K. Ray, R. Mitra, Electrical and thermophysical properties of $\mathrm{ZrB} 2$ and $\mathrm{HfB} 2$ based composites, J. Eur. Ceram. Soc. 32 (2012) 2545-2555.

[33] M. Patel, V.V.B. Prasad, V. Jayaram, Heat conduction mechanisms in hot pressed $\mathrm{ZrB} 2$ and $\mathrm{ZrB} 2-\mathrm{SiC}$ composites, J. Eur. Ceram. Soc. 33 (2013) 1615-1624.

[34] M. Shahedi Asl, B. Nayebi, Z. Ahmadi, M.J. Zamharir, M. Shokouhimehr, Effects of carbon additives on the properties of ZrB2-based composites: A review, Ceram. Int. 44 (2018) 7334 7348.

[35] Y. Achenani, M. Saâdaoui, A. Cheddadi, G. Bonnefont, G. Fantozzi, Finite element modeling of spark plasma sintering: Application to the reduction of temperature inhomogeneities, case of alumina, Mater. Des. 116 (2017) 504-514.

[36] C. Wang, L. Cheng, Z. Zhao, FEM analysis of the temperature and stress distribution in spark plasma sintering: Modelling and experimental validation, Comput. Mater. Sci. 49 (2010) 351-362.

[37]A. Pavia, L. Durand, F. Ajustron, V. Bley, G. Chevallier, A. Peigney, C. Estournès, Electro-thermal measurements and finite element method simulations of a spark plasma sintering device, J. Mater. Process. Technol. 213 (2013) 1327-1336.

[38] F. Nakamori, Y. Ohishi, H. Muta, K. Kurosaki, K. Fukumoto, S. Yamanaka, Mechanical and thermal properties of bulk ZrB2, J. Nucl. Mater. 467 (2015) 612-617.

[39] E. Zapata-Solvas, D.D. Jayaseelan, H.T. Lin, P. Brown, W.E. Lee, Mechanical properties of $\mathrm{ZrB} 2$ and HfB2-based ultra-high temperature ceramics fabricated by spark plasma sintering, J. Eur. Ceram. Soc. 33 (2013) 1373-1386. 